\title{
On the Origin of the Order-Disorder Structures (Polytypes) of Some Transition Metal Hexacyano Complexes
}

\author{
SUSAN JAGNER
}

Department of Inorganic Chemistry, Chalmers University of Technology and University of Göteborg, S-412 96 Göteborg, Sweden

Potassium hexacyanometallates(III), $\mathrm{K}_{3}\left[\mathrm{M}(\mathrm{CN})_{6}\right], \mathrm{M}=\mathrm{Cr}, \mathrm{Mn}, \mathrm{Fe}, \mathrm{Co}$, crystallize at room temperature with structures which are periodic in two dimensions only, i.e. which can be described in terms of ordered, equivalent layers the mode of stacking of which is disordered. Trends in the order-disorder behaviour of these compounds have been studied by examining differences in Madelung-potential arising from different stacking types. It would appear that the order-disorder behaviour (polytypism) of these compounds is thermodynamic in origin and arises from the similarity between the $M-(C)-N$ and $K \cdots N$ distances combined with the approximate equality of the effective positive charges on the potassium and metal ions.

Several theories have been proposed to account for the formation of polytypes, these falling into two main groups: those based essentially on kinetic approaches to growth mechanisms, and those based on thermodynamic considerations (see e.g. Refs. 1-2 and references therein). In connection with structural studies on hexacyano complexes, several compounds crystallizing with disordered (polytypic) crystal structures ${ }^{3-6}$ at room temperature have been encountered. The disorder is of OD type ${ }^{7}$ i.e. the structures can be described in terms of ordered, equivalent layers whose mode of stacking is disordered. Invariably anhydrous potassium salts were found to crystallize with OD structures, ${ }^{3-6}$ whereas $e . g$. hydrated sodium compounds were fully ordered. ${ }^{8}$ Moreover, the order-disorder in the $K_{3}\left[M(C N)_{6}\right]$ series, $\mathrm{M}=\mathrm{Cr}, \mathrm{Mn}, \mathrm{Fe}, \mathrm{Co},{ }^{3-5}$ appeared to show a regular trend from chromium to cobalt, suggesting that there might be a correlation between the disorder and the chemical bonding within the hexacyanometallate(III) ions. A closer examination of the crystal structures of these compounds therefore seemed to be justified, it being hoped that it might prove possible to clarify why $\mathrm{K}_{3}\left[\mathrm{M}(\mathrm{CN})_{6}\right]$ crystallize with $\mathrm{OD}$ rather than with fully-ordered crystal structures.

\section{THE OD STRUCTURES OF $\mathrm{K}_{3}\left[\mathrm{Mn}(\mathrm{CN})_{6}\right]$}

All members of the $\mathrm{K}_{3}\left[\mathrm{M}(\mathrm{CN})_{6}\right]$ series, $\mathrm{M}=\mathrm{Cr}, \mathrm{Mn}, \mathrm{Fe}$, Co, crystallize with comparable OD structures $^{3-5}$ and can be described in terms of ordered layers of formal symmetry $\operatorname{Pma}(n)$, the stacking of which is disordered. As is usual for OD structures, ${ }^{7}$ the $c$ direction has been chosen to be that of non-periodicity and the pertaining symmetry elements are enclosed in parentheses. 


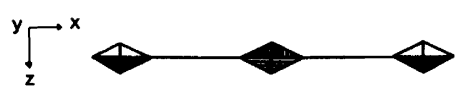

(a)

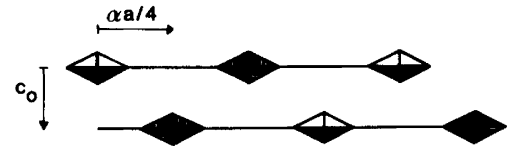

(b)

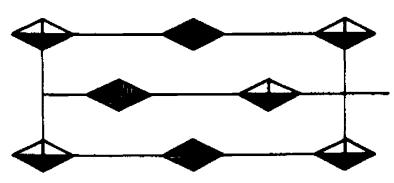

(c)

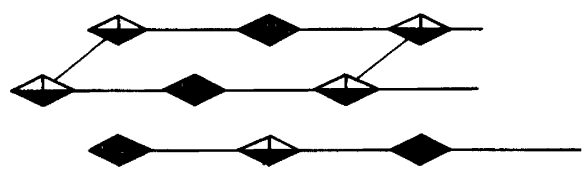

(d)
Fig. 1. Schematic representation of (a) an OD layer, $L_{p}$, symmetry $P m a(n)$, (b) a pair of layers $L_{p}$ and $L_{p+1}$, symmetry $P \operatorname{ma}(n)\left\{c_{2}\right.$ $\left.n_{2, \frac{1}{2}}\left(n_{\frac{1}{2}, 1}\right)\right\}$ and the stacking of layers in (c) the $\mathrm{MDO}_{1}(P$ can $)$ and (d) the $\mathrm{MDO}_{2}\left(P 2_{1} / a\right)$ structures. $c_{0}$ is the unit vector perpendicular to the layers in the direction of nonperiodicity; $\alpha$ can take the value +1 or -1 . Notation: empty triangles: $y$, filled triangles: $\bar{y}$, vertically shaded triangles: $\frac{1}{2}-y$, horizontally shaded triangles: $\frac{1}{2}+y$.

The layer symmetry may be represented schematically as in Fig. 1a. In the $K_{3}\left[M(C N)_{6}\right]$ series, any layer, $L_{p}$, is related to the next, $L_{p+1}$, by the partial symmetry elements $p, p+1\left[c_{2} n_{2, \frac{1}{2}}\left(n_{\frac{1}{2}, 1}\right)\right]$ or ${ }_{p, p+1}\left[c_{2} n_{2, \frac{1}{2}}\left(n_{\frac{1}{2}, 1}\right)\right]$, these operations giving rise to a single pair of layers (Fig. 1b). The element $c_{2}$ implies a glide plane perpendicular to $a$ with the translation period $c_{0}$, the layer spacing. Similarly, $n_{2, \frac{1}{2}}$ involves translation periods of $c_{0}$ and $a / 4$, respectively, while $n \frac{1}{2,1}$ implies translation periods of $a / 4$ and $b / 2$. A translation along $-a$ is denoted with a minus sign. The total symmetry of any pair of consecutive layers can thus be expressed by the OD groupoid symbol:

\section{$\operatorname{Pma}(n)$ \\ $\left\{c_{2} n_{2, \frac{1}{2}}\left(n_{2}, 1\right)\right\}$}

This symbol characterizes the family of structures as which any member of the $\mathrm{K}_{3}\left[\mathrm{M}(\mathrm{CN})_{6}\right]$ series crystallizes and corresponds to the space group of a fully-ordered structure.

Alternatively, a given layer, $L_{p}$, may be seen (Fig. 1b) to be converted into the next, $L_{p+1}$, by the translation $\alpha a / 4+c_{0}$, where $c_{0}$ is the unit vector perpendicular to the layers in the direction of non-periodicity, and $\alpha$ can take the value +1 or -1 . If $\alpha$ is alternately -1 and +1 (Fig. 1c), an ordered structure with orthorhombic symmetry, space group Pcan, is obtained. This is one of the two "structures of maximum degree of order", ${ }^{7} \mathrm{MDO}$, and is denoted $\mathrm{MDO}_{1}$. In this structure the layers $L_{p+2}, L_{p+4}, L_{p+6}$, etc. lie directly above $L_{p}$ in the $c$ direction.

An oblique stacking of layers, i.e. $\alpha=+1$ or -1 only, leads to an ordered monoclinic structure, $\mathrm{MDO}_{2}$, space group $P 2_{1} / a$ (Fig. 1d), that for which $\alpha=-1$ being a twin to that for 
which $\alpha=+1$. In the monoclinic structure the layers $L_{p+4}, L_{\mathrm{p}+8}$, etc. lie directly over $L_{p}$ in the direction of non-periodicity, while the layers $L_{p+2}, L_{p+6}$ are displaced by $a / 2$ relative to $L_{p}$.

Stacking sequences intermediate between these two extremes result in a non-periodic $c$ direction, which implies the presence of diffuse streaks in reciprocal space. The closer the stacking sequence is to that of one of the ordered extreme structures, the weaker the streaks in reciprocal space and the more pronounced the discrete reflections on these streaks corresponding to the relevant MDO structure. In principle, each crystal of a given $\mathrm{K}_{3}\left[\mathrm{M}(\mathrm{CN})_{6}\right]$, e.g. of $\mathrm{K}_{3}\left[\mathrm{Cr}(\mathrm{CN})_{6}\right]$, will exhibit a unique stacking sequence and can be described in terms of smaller or larger contributions from the MDO structures. In practice, however, for each of the compounds one of the MDO structures was found to dominate. ${ }^{3-5}$

\section{RELATIVE STABILITY OF $\mathrm{MDO}_{1}$ VERSUS $\mathrm{MDO}_{2}$ IN $\mathrm{K}_{3}\left[\mathrm{M}(\mathrm{CN})_{6}\right]$}

Observed trends. There would appear to be a stabilization of the $\mathrm{MDO}_{2}$ structure and a destabilization of the $\mathrm{MDO}_{1}$ structure from $\mathrm{M}=\mathrm{Cr}$ to $\mathrm{M}=\mathrm{Co}$. Crystals of potassium hexacyanochromate(III) exhibit well-defined intensity maxima, corresponding to the orthorhombic $\mathrm{MDO}_{1}$, on exceedingly weak streaks and very few maxima corresponding to the monoclinic $\mathrm{MDO}_{2}$ structure. ${ }^{3}$ Potassium hexacyanomanganate(III) crystallizes with appreciable contributions from both $\mathrm{MDO}_{1}$ and $\mathrm{MDO}_{2}$, although the $\mathrm{MDO}_{2}$ structure dominates slightly and was that solved. ${ }^{4}$ Potassium hexacyanoferrate(III) and potassium hexacyanocobaltate(III), to an even greater extent, crystallize almost exclusively as $\mathrm{MDO}_{2}{ }^{5}$ Both the orthorhombic and the monoclinic structures of $\mathrm{K}_{3}\left[\mathrm{Fe}(\mathrm{CN})_{6}\right]$ have, however, been determined in an independent investigation. ${ }^{9}$

Refinement of the structures of $\mathrm{K}_{3}\left[\mathrm{Cr}(\mathrm{CN})_{6}\right]$ and $\mathrm{K}_{3}\left[\mathrm{Co}(\mathrm{CN})_{6}\right]$ with and without constraints with respect to the partial symmetry operations of the OD groupoid symbol indicated that for $\mathrm{K}_{3}\left[\mathrm{Cr}(\mathrm{CN})_{6}\right]$ the model based on space-group symmetry only was that most satisfactory. ${ }^{10}$ For $\mathrm{K}_{3}\left[\mathrm{Co}(\mathrm{CN})_{6}\right]$ the model in which the partial symmetry elements were preserved was acceptable if reflections required to be systematically absent by the OD groupoid but not by $P 2_{1} / a$ were assigned $F_{o}=0.0$ and given double weight. Otherwise the model based on space-group symmetry only was superior. Thus, the partial symmetry elements of the OD groupoid, and specifically the mirror plane of the OD layer, appear to be more exactly complied with in $\mathrm{K}_{3}\left[\mathrm{Co}(\mathrm{CN})_{6}\right]$ than in $\mathrm{K}_{3}\left[\mathrm{Cr}(\mathrm{CN})_{6}\right]$.

Calculations. Ideally the configuration of any pair of consecutive layers is the same regardless of whether the stacking is of $\mathrm{MDO}_{1}$ or $\mathrm{MDO}_{2}$ type. Any difference in energy between the two stacking types ought therefore to be apparent on comparison of interactions between a given layer, $L_{p}$, and the next-but-one, $L_{p+2}$. Since the distance between $L_{p}$ and $L_{p+2}$ is of the order of $13 \AA$, interactions would be expected to be predominantly electrostatic in nature.

Modified Madelung-potential calculations of Evjen type ${ }^{11}$ were carried out taking into account electrostatic interactions between a formula unit of $\mathrm{K}_{3}\left[\mathrm{M}(\mathrm{CN})_{6}\right]$ in $L_{p+2}$ and ions in a finite section of $L_{p}$, e.g. for a given $\mathrm{M}^{q+}$ in $x, y, z$ in $L_{p+2}$ all interactions within $x \pm 0.5000$ and $y \pm 0.5000$ in $L_{p}$ were included. Interactions with ions on the edges of the rectangular section were assigned weight 0.25 and those with ions on the faces were assigned weight 0.50 . Since previous investigations ${ }^{12}$ indicated that the effective charge on carbon is fairly constant, $\mathrm{C}$ atoms were assigned $q=0, \mathrm{~K}$ ions were assumed to have charge $+1, \mathrm{M}$ was assigned charge $q+$ and $N$ atoms were assigned charge $\left(\frac{1}{2}+q / 6\right)^{-}$. In this way the difference in Acta Chem. Scand. A 39 (1985) No. 10 
electrostatic energy between $\mathrm{MDO}_{1^{-}}$and $\mathrm{MDO}_{2}$-type stacking could be estimated as a quadratic in $q$. Essentially two types of calculation were carried out:

(i) Constrained $O D$ symmetry. In these calculations the coordinates used were those obtained in the constrained refinement of $\mathrm{K}_{3}\left[\mathrm{Cr}(\mathrm{CN})_{6}\right]$ and $\mathrm{K}_{3}\left[\mathrm{Co}(\mathrm{CN})_{6}\right]$, i.e. with the partial symmetry operations of the OD groupoid symbol preserved. ${ }^{10}$ Layers were defined as indicated in Fig. 2 with the $K(2)$ ions situated on the mirror planes. Since $K(2)$ lie in effect between layers (Fig. 2) there are several ways in which the layers could be chosen with respect to inclusion or omission of $\mathrm{K}(2)$. The above choice is, however, the only possibility if the layer symmetry $P m a(n)$ is to be preserved exactly. The formula unit in $L_{p+2}$ comprised $M$ and $6 N$, within the same complex ion, one $K(1)$, and two $K(2)$ chosen such that both $K(2)$ were situated on the boundary between $L_{p+1}$ and $L_{p+2}$ (see Fig. 2). For $\mathrm{K}_{3}\left[\mathrm{Cr}(\mathrm{CN})_{6}\right]$ and $\mathrm{K}_{3}\left[\mathrm{Co}(\mathrm{CN})_{6}\right]$ the $\mathrm{MDO}_{2}$ - and $\mathrm{MDO}_{1}$-type interactions, respectively, were obtained by translating $L_{p+2}$ through $a / 2$ relative to $L_{p}$. Since $K_{3}\left[\mathrm{Mn}(\mathrm{CN})_{6}\right]$ and $\mathrm{K}_{3}\left[\mathrm{Fe}(\mathrm{CN})_{6}\right]$ had not been refined with constraints with respect to the ideal OD symmetry it was not possible to carry out this type of calculation for these compounds.

(ii) Space-group symmetry only. For $\mathrm{K}_{3}\left[\mathrm{Cr}(\mathrm{CN})_{6}\right]$ the coordinates used were those of the real structure (Pcan) and interactions between a formula unit in $L_{p+2}$ (chosen as above) and ions in $L_{p}$ were calculated.

For $\mathrm{K}_{3}\left[\mathrm{Co}(\mathrm{CN})_{6}\right]$ preliminary calculations showed that interactions within the "real" and ideal $\mathrm{MDO}_{2}$ structures were practically identical. Moreover, the constrained model had been found ${ }^{10}$ to be superior if systematically absent reflections not required to be absent by
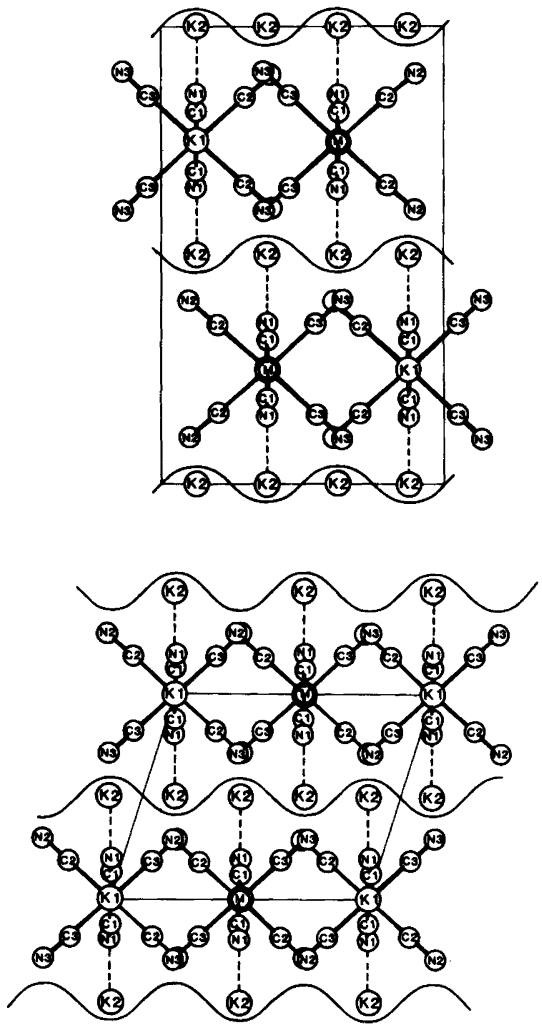

Fig. 2. Projections of the $\mathrm{MDO}_{1}$ and $\mathrm{MDO}_{2}$ structures of $\mathrm{K}_{3}\left[\mathrm{M}(\mathrm{CN})_{6}\right]$ along [010]. The $a$ axis is horizontal. Full lines indicate unit-cell boundaries, wavy lines show the definition of the OD layers, while broken lines indicate the partial mirror planes of these layers. 
space-group symmetry were given double weight. Since this is a reasonable assignment, bearing in mind that photographs of substances crystallizing with OD structures usually have to be over-exposed in order that the OD groupoid can be determined with certainty, the constrained model was taken to be that appropriate for $\mathrm{K}_{3}\left[\mathrm{Co}(\mathrm{CN})_{6}\right]$. Thus no calculations of type (ii) were carried out for $\mathrm{K}_{3}\left[\mathrm{Co}(\mathrm{CN})_{6}\right]$.

For $\mathrm{K}_{3}\left[\mathrm{Mn}(\mathrm{CN})_{6}\right]$ and $\mathrm{K}_{3}\left[\mathrm{Fe}(\mathrm{CN})_{6}\right]$ it was not possible to calculate interactions within the ideal OD structures for comparison with the real structure. A rough estimate of the difference in energy resulting from the orthorhombic stacking mode can be obtained by translating $L_{p+2}$ through $a / 2$ relative to $L_{p}$. This procedure is not, however, strictly correct since any deviations from ideal $\mathrm{MDO}_{2}$ symmetry in the monoclinic structure will be imposed on the orthorhombic. Calculations for $\mathrm{K}_{3}\left[\mathrm{Mn}(\mathrm{CN})_{6}\right]$ and $\mathrm{K}_{3}\left[\mathrm{Fe}(\mathrm{CN})_{6}\right]$ involved two layers only, i.e. $L_{p}$ and $L_{p+2}$. For $\mathrm{K}_{3}\left[\mathrm{Fe}(\mathrm{CN})_{6}\right]$ interactions between a formula unit in $L_{p+2}$ and ions in $L_{p}$ were also calculated using the coordinates for the orthorhombic and monoclinic forms determined by Figgis, Skelton and White, ${ }^{9 b}$ here denoted FSW.

\section{RESULTS}

The results of the calculations described under (i) and (ii) above are summarized in Table 1. The difference in energy between the two packing types, which is obtained as a quadratic in $q$, the charge on $M$, is seen to be small when the charge on the central metal atom is of the same order as that on $\mathrm{K}^{+}$. Examination of the individual terms in the calculation shows that $\mathbf{M}-\mathbf{N}$ and $\mathrm{K}(1)-\mathrm{N}$ interactions are of similar magnitude in each of the four compounds (Table 2). Thus the similarity between $M-(C)-N$ distances and $K \cdots N$ contacts has validity even on a longer-range basis. Although the calculations show a trend towards a stabilization of the $\mathrm{MDO}_{1}$ structure versus $\mathrm{MDO}_{2}$ from $\mathrm{M}=\mathrm{Co}$ to $\mathrm{M}=\mathrm{Cr}$, i.e. a slight decrease in $\Delta U$, the experimental observation that $\mathrm{K}_{3}\left[\mathrm{Cr}(\mathrm{CN})_{6}\right]$ crystallizes almost exclusively as the orthorhombic structure is not reproduced. Nor is it apparent from the calculations why the model not requiring strict compliance with the partial symmetry operations of the OD groupoid proved to be superior in the refinement of the structure.

\section{DISCUSSION}

That $\mathrm{K}_{3}\left[\mathrm{M}(\mathrm{CN})_{6}\right]$ crystallize as $\mathrm{OD}$ structures would appear to be thermodynamic in origin and a consequence of the similarity between $K \cdots N$ contacts and $M-(C)-N$ distances. The absence of water of crystallization necessitates the coordination of potassium ions by nitrogen atoms of the cyanide groups and leads to the formation of layers composed of $\left[\mathrm{M}(\mathrm{CN})_{6}\right]^{3-}$ and $\mathrm{K}(1)^{+} \ldots \mathrm{N} \times 6$ octahedra with approximately equal dimensions. These layers are connected through $\mathrm{K}(2)^{+} \cdots \mathrm{N} \times 6$ trigonal prisms, there being two modes of packing, as described above. The calculations show that the similarity between $K \cdots N$ and $M-(C)-N$ is not in itself a sufficient requirement for order-disorder behaviour but that the difference in energy between the two packing types is minimal only when the charge on $\mathbf{M}$ is of the same magnitude as that on $\mathrm{K}^{+}$.

The charge on $\mathrm{M}$ is a consequence of $\sigma$ and $\pi$ bonding contributions to the $\mathrm{M}-\mathrm{C}$ bond. Electron donation from cyanide to metal has been shown to increase with increasing effective nuclear charge on $\mathrm{M}$, i.e. from $\mathrm{M}=\mathrm{Cr}$ to $\mathrm{M}=\mathrm{Co}^{3-5,12,13}$ and will tend to reduce the charge on M. Metal $\rightarrow \pi^{*}$ (ligand) transfer will tend to increase the charge on $M$ and is 


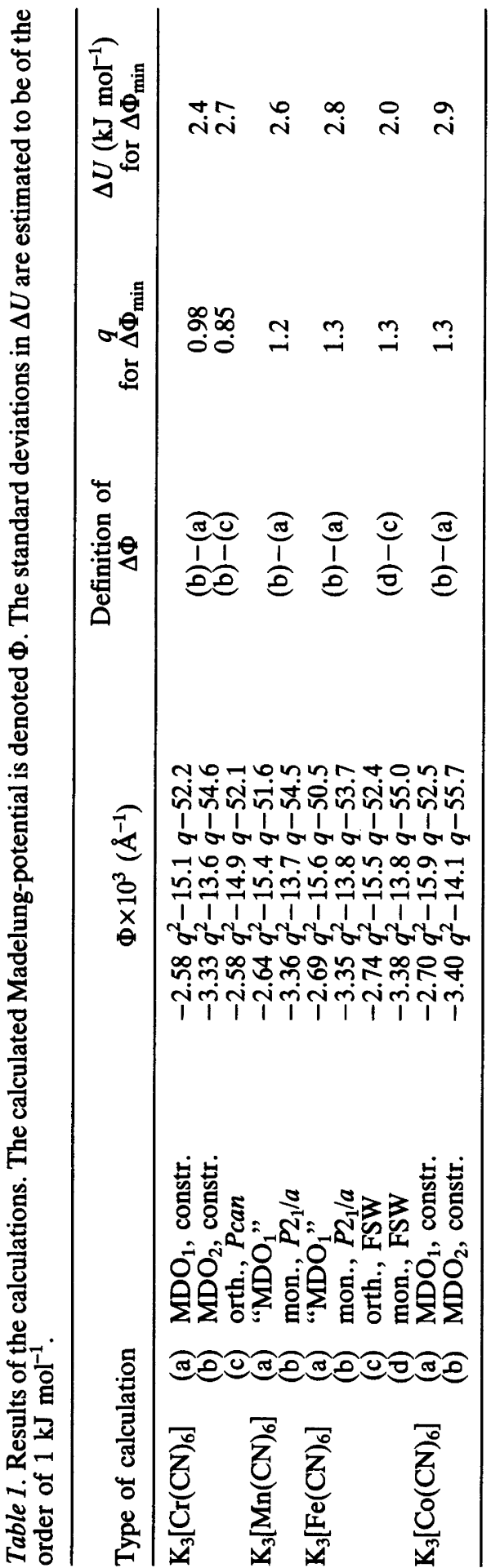

Acta Chem. Scand. A 39 (1985) No. 10 
Table 2. Comparison between $\mathrm{M} \rightarrow \mathrm{N}$ and $\mathrm{K} \rightarrow \mathrm{N}$ interactions $\left(\AA^{-1}\right), L_{p+2}$ to $L_{p}$.

\begin{tabular}{|c|c|c|c|}
\hline Compound & $\Sigma \frac{1}{M-N}$ & $\Sigma \frac{1}{\mathrm{~K}(1)-\mathrm{N}}$ & $\Sigma \frac{1}{K(2)-N}$ \\
\hline $\begin{aligned} & \mathrm{K}_{3}\left[\mathrm{Cr}(\mathrm{CN})_{6}\right] \mathrm{MDO}_{1} \text {, constr. } \\
& \mathrm{MDO}_{2} \text {, constr. } \\
& \text { orth., } \text { Pcan }\end{aligned}$ & $\begin{array}{l}0.8573 \\
0.8576 \\
0.8573\end{array}$ & $\begin{array}{l}0.8576 \\
0.8573 \\
0.8577\end{array}$ & $\begin{array}{l}1.1221 \\
1.1218 \\
1.1221\end{array}$ \\
\hline $\begin{array}{l}\mathrm{K}_{3}\left[\mathrm{Mn}(\mathrm{CN})_{6}\right] \\
\text { "MDO }{ }_{1}^{\prime} \\
\text { mon., } P 2_{1} / a\end{array}$ & $\begin{array}{l}0.8670 \\
0.8672\end{array}$ & $\begin{array}{l}0.8672 \\
0.8670\end{array}$ & $\begin{array}{l}1.1336 \\
1.1333\end{array}$ \\
\hline $\begin{array}{c}\mathrm{K}_{3}\left[\mathrm{Fe}(\mathrm{CN})_{6}\right] \\
\text { "MDO" } \\
\text { mon., } P 2_{1} / a \\
\text { orth., FSW } \\
\text { mon., FSW }\end{array}$ & $\begin{array}{l}0.8690 \\
0.8692 \\
0.8737 \\
0.8738\end{array}$ & $\begin{array}{l}0.8692 \\
0.8690 \\
0.8738 \\
0.8736\end{array}$ & $\begin{array}{l}1.1362 \\
1.1360 \\
1.1412 \\
1.1418\end{array}$ \\
\hline $\begin{array}{l}\mathrm{K}_{3}\left[\mathrm{Co}(\mathrm{CN})_{6}\right] \\
\mathrm{MDO}_{1}, \text { constr. } \\
\mathrm{MDO}_{2} \text {, constr. }\end{array}$ & $\begin{array}{l}0.8783 \\
0.8785\end{array}$ & $\begin{array}{l}0.8785 \\
0.8783\end{array}$ & $\begin{array}{l}1.1480 \\
1.1478\end{array}$ \\
\hline
\end{tabular}

expected to increase with decreasing effective nuclear charge on $\mathrm{M}$, i.e. from $\mathrm{Co} \rightarrow \mathrm{Cr}$, but at the same time to increase with the number of $d$ electrons available. The value $q \approx 1$ obtained in the calculations would appear to be consistent with moderate $\pi$ bonding throughout the series. That $q$ increases slightly from chromium to cobalt also seems reasonable. ${ }^{12}$

Thus whereas sodium hexacyanometallates(III), e.g. $\mathrm{Na}_{3}\left[\mathrm{Fe}(\mathrm{CN})_{6}\right] \cdot 2 \mathrm{H}_{2} \mathrm{O}^{14}$ and $\mathrm{Na}_{3}\left[\mathrm{Fe}(\mathrm{CN})_{6}\right],{ }^{15}$ and hydrated potassium hexacyanometallates(III) might be expected to crystallize as fully-ordered structures, the packing of $\mathrm{K}^{+} \ldots \mathrm{N} \times 6$ and $\left[\mathrm{M}(\mathrm{CN})_{6}\right]^{3-}$ octahedra would be expected to lead to order-disorder behaviour. That such structures are indeed formed is, moreover, a consequence of metal-ligand $\pi$ bonding which causes the charge on $\mathrm{M}$ to be approximately the same as that on $\mathrm{K}^{+}$. Thus, even if the length of $\mathrm{M}-\mathrm{X}$ in an $\mathrm{MX}_{6}^{3-}$ octahedron were of the same order as $\mathrm{K} \cdots \mathrm{X}$, it would be unlikely that $\mathrm{K}_{3}\left[\mathrm{MX}_{6}\right]$ would crystallize with an OD structure of the above type if, for instance, $\mathrm{X}^{-}$were a $\sigma$ donor, only.

The small difference in energy, ca. $3 \mathrm{~kJ} \mathrm{~mol}^{-1}$, between the two packing types implies that the monoclinic and orthorhombic forms are thermodynamically stable for each member of the series and that the occurrence of the less stable form can be explained on a statistical basis. The experimental trend in monoclinic versus orthorhombic packing has not, however, been reproduced completely in that the monoclinic form has been found to be that most stable for $\mathrm{K}_{3}\left[\mathrm{Cr}(\mathrm{CN})_{6}\right]$. The decrease in the difference in energy between the two packing types from $\mathrm{M}=\mathrm{Co}$ to $\mathrm{M}=\mathrm{Cr}$ could explain an increased contribution from the orthorhombic form but perhaps not to the extent encountered in $\mathrm{K}_{3}\left[\mathrm{Mn}(\mathrm{CN})_{6}\right]$ or $\mathrm{K}_{3}\left[\mathrm{Cr}(\mathrm{CN})_{6}\right]$. The difference in energy between the monoclinic and orthorhombic (FSW) forms of $\mathrm{K}_{3}\left[\mathrm{Fe}(\mathrm{CN})_{6}\right]$ is slightly, if not significantly, less than that between the monoclinic ${ }^{5}$ form and its calculated $\mathrm{MDO}_{1}$ counterpart. It is not unconceivable that a comparison between the orthorhombic (Pcan) and the real monoclinic structure of $\mathrm{K}_{3}\left[\mathrm{Cr}(\mathrm{CN})_{6}\right]$, had this been possible, would have also resulted in a smaller difference in energy than obtained here (Table 1).

In a layer of $\mathrm{K}_{3}\left[\mathrm{Co}(\mathrm{CN})_{6}\right], \mathrm{K}^{+} \ldots \mathrm{N} \times 6$ and $\mathrm{M}(\mathrm{CN})_{6}^{3-}$ octahedra fit well together as a consequence of the close similarity between $M-(C)-N$ and $K \cdots N$. As $M-(C)-N$ distances 
increase from $\mathrm{Co} \rightarrow \mathrm{Cr}$, the discrepancy between the two sets of distances might be expected to increase, despite a general expansion of $\mathrm{K} \cdots \mathrm{N}$ (Table 2). It would seem reasonable that this might result in an increased tendency towards lower symmetry, i.e. non-compliance with the mirror plane, and lowering of the site symmetry for $M$ and $K(1)$ from $2 / m$ to 2 (orth) and $\overline{1}$ (mon). Between room temperature and $4.2 \mathrm{~K}, \mathrm{~K}_{3}\left[\mathrm{Cr}(\mathrm{CN})_{6}\right]$ undergoes a phase transition and the structure at $4.2 \mathrm{~K}$ can be described in terms of a four-twin triclinic model with stacking disorder. ${ }^{16}$

The $\mathbf{K}(2)^{+}$ions appear to act as relays between the layers, the different packing types giving rise to slightly different distortions of the trigonal prisms. ${ }^{17} \mathrm{~K}(2)-\mathrm{N}$ interactions would also seem to favour monoclinic packing for all four members of the series (Table 2).

Acknowledgements. I wish to thank Professor Nils-Gösta Vannerberg for valuable discussions. Financial support from the Swedish Natural Science Research Council (NFR) is gratefully acknowledged.

\section{REFERENCES}

1. Trigunayat, G.C. and Chadha, G.K. Phys. Status Solidi A 4 (1971) 9.

2. Trigunayat, G.C. and Chadha, G.K. Phys. Status Solidi A 4 (1971) 281.

3. Jagner, S., Ljungström, E. and Vannerberg, N.-G. Acta Chem. Scand. A 28 (1974) 623.

4. Vannerberg, N.-G. Acta Chem. Scand. 24 (1970) 2335.

5. Vannerberg, N.-G. Acta Chem. Scand. 26 (1972) 2863.

6. Jagner, S. Acta Chem. Scand. A 29 (1975) 255.

7. Dornberger-Schiff, K. Lehrgang über OD-Strukturen, Akad.-Verlag, Berlin 1966.

8. a. Tullberg, A. and Vannerberg, N.-G. Acta Chem. Scand. A 28 (1974) 551; b. Ljungström, E. Acta Chem. Scand. A 31 (1977) 104.

9. a. Figgis, B.N., Gerloch, M. and Mason, R. Proc. Roy. Soc. London Ser. A 309 (1969) 91; b. Figgis, B.N., Skelton, B.W. and White, A.H. Aust. J. Chem. 31 (1978) 1195.

10. Hazell, R.G. and Jagner, S. Acta Crystallogr. B 31 (1975) 1412.

11. Evjen, H.M. Phys. Rev. 39 (1932) 675.

12. Vannerberg, N.-G. Chem. Scr. 9 (1976) 122.

13. Alexander, J.J. and Gray, H.B. J. Am. Chem. Soc. 90 (1968) 4260.

14. Katila, T., Leskelä, M., Niinistö, L., Riski, K.J., Valkonen, J. and Ylä-Jääski, J. J. Solid State Chem. 35 (1980) 341.

15. Leskelä, M. and Valkonen, J. XI Nordiske Strukturkjemikermøte, Program og Abstrakter, Universitetet i Troms $\varnothing$, Troms $\emptyset 1984$, p. 47.

16. Figgis, B.N., Reynolds, P.A. and Williams, G.A. Acta Crystallogr. B 37 (1981) 504.

17. Ljungström, E. Crystal Structures of Some $\pi$ Acceptor Ligand Complexes of Vanadium, Chromium and Manganese, Thesis, Department of Inorganic Chemistry, Chalmers University of Technology and University of Göteborg, Göteborg 1979.

Received May 10, 1985. 